\title{
Controversies in the management of pelvic fracture urethral distraction defects
}

\author{
Pankaj Mangalkumar Joshi (D), Vikram Batra (D), Sanjay B. Kulkarni
}

Cite this article as: Joshi PM, Batra V, Kulkarni SB. Controversies in the management of pelvic fracture urethral distraction defects. Turk J Urol 2019; 45(1): 1-6.

ORCID IDs of the authors: P.M.J. 0000-0002-2233-7785; V.B. 0000-0002-7503-6193; S.B.K. 0000-0002-6942-4579.

Kulkarni Reconstructive Urology Centre, Pune, Idnia

Submitted:

17.08.2018

Accepted:

11.10.2018

Corresponding Author: Pankaj Mangalkumar Joshi E-mail:

drpankajmjoshi@gmail.com

(C) Copyright 2019 by Turkish Association of Urology

Available online at turkishjournalofurology.com

\begin{abstract}
Pelvic fracture associated urethral injury (PFUI) is a sequel of blunt pelvic trauma. The published rate of urethral injury varies from 5-25\% in different series. Management includes options from primary realignment to delayed anastomotic urethroplasty. Anastomotic urethroplasty include an elaborated progressive perineal approach and combined transpubic approach. Though the treatment and approach is well accepted across the globe, controversies do exist. Through this section we would debate the literature regarding some controversial issues in management of PFUI. The aim of this article was to evaluate and elucidate upon the controversies that surround the PFUI repair in this era.
\end{abstract}

The following controversial and pertinent issues with respect to the repair of such injuries were reviewed: 1. Primary realignment versus delayed repair of PFUI,

2. Necessity of inferior pubectomy,

3. Predictability of inferior wedge pubectomy,

4. Spatulation of distal bulbar and proximal urethral ends,

5. Nomenclature of bulbar urethra.

This study and evaluation comes from a tertiary high-volume center of reconstructive urology. Apart from our own center's experience the literature was reviewed for evidence synthesis and framing an opinion. Each of the above principles and surgical steps regarding management of pelvic fracture urethral injury was dealt with sequentially and evidence based literature reviewed. Only data from high volume urethroplasty centers and peer reviewed articles which made significant contribution were considered. The data was analyzed and conclusion drawn. On evidence collection there was sparse and scattered evidence in favour of early realignment even after technical advancement. Delayed anastomotic urethroplasty with progressive perineal approach is recommended. Inferior wedge pubectomy cannot be predicted based upon current conventional imaging.

The injury and urethral distraction has a wide spectrum and with the fallibility of imaging, inferior pubectomy is a necessary steps under relevant settings to gain access to the posterior urethra. There are multitude of ways to spatulate urethra at either end although literature does not provide a superior way. Spatulation of distal urethra dorsally and leaving the proximal sphincter active urethra unspatulated is be the best scientifically. There is a need to reclassify the bulbar urethra to the penoscrotal junction to avoid under mobilization of bulbar urethra during the repair. There is no conclusive article addressing the controversial issues highlighted in this article. Adequate mobilization of bulbar urethra should be done till penoscrotal junction. Inferior pubectomy as a technique cannot be predicted and its utility cannot be underestimated. The spatulation of urethra can be done in multiple ways. Current anatomical definition of bulbar urethra is erroneous to imply urethra only in the bulb but with respect to surgery it should be extended till the penoscrotal junction.

Keywords: Bulbar urethra; inferior pubectomy; pelvic fracture urethral injury; urethral stricture. 


\section{Introduction}

Pelvic fracture associated urethral injury is sequel of blunt pelvic trauma. The published rate of urethral injury varies from 5-25\% in different series. ${ }^{[1]}$ This is associated with superior displacement of bladder and prostatic urethra. Management includes options from primary realignment to delayed anastomotic urethroplasty. ${ }^{[2]}$ Steps of surgery include simple perineal approach to elaborated perineal approach and combined transpubic approach. Though the treatment and approach is well accepted across the globe, controversies do exist. Through this section we would debate the literature regarding some controversial issues in management of Pelvic Fracture Urethral Distraction Defects (PFUDD).

The aim of this article was to evaluate and elucidate upon the controversies that surround the PFUDD repair in this era. The objective is to come to a rational conclusion as per the available experience and the literature.

\section{Material and methods}

This study and evaluation comes from a tertiary high-volume center of reconstructive urology. More than 1192 patients with simple to complex posterior urethral injury due to pelvic fracture have undergone surgery in our center. We also have experience of operating in more than 30 countries including Live urethroplasty workshop. We keep a prospective database of all patients who are referred and operated. Apart from our own center's experience the literature was reviewed for evidence synthesis and framing an opinion. The following controversial and pertinent issues with respect to the repair of such injuries were reviewed:

1. Primary realignment versus delayed repair of pelvic injury,

2. Necessity of inferior pubectomy,

3. Predictability of inferior wedge pubectomy,

4. Spatulation of distal bulbar and proximal urethral ends,

5. Nomenclature of bulbar urethra.

Each of the above surgical steps of progressive perineal approach was dealt with sequentially and evidence based literature reviewed. Only data from high volume urethroplasty centers and peer reviewed articles which made significant contribution were considered. The data was analyzed and conclusion drawn.

\section{Results}

\section{Primary realignment versus delayed repair}

The issue of primary realignment after PFUDD against suprapubic catheter placement and delayed anastomotic urethroplasty after 3 months is being constantly debated. Modern techniques of endourology were introduced in 1980. The techniques evolved by using transurethral and transvesical approach in conjunction with fluoroscopy. This gave birth to the option of early primary realignment after PFUDD. Proponents of this technique suggest that it avoids delayed surgery in some patients. ${ }^{[2]}$ If there is a recurrence then the gap is small. As there is no manipulation of periprostatic tissues there is less risk of erectile dysfunction. Many studies have compared the success rates of realignment versus delayed repair. ${ }^{[3-12]}$

Webster et al. ${ }^{[1]}$ in their comprehensive review of 538 patients reported that stricture developed in $97 \%$ of the patients treated initially with suprapubic catheter, and in $53 \%$ of them who underwent mixed techniques of primary realignment. This study analyzed rates of impotence after both approaches. The rates of impotence after primary realignment, and delayed repair were 36 , and $19 \%$, respectively. This study did not involve the advanced endourological and fluoroscopic-guided procedures and hence suffered from more adverse results. The most current data are more favorable. According to Mundy ${ }^{[13]}$ endoscopic realignment may impede urethroplasty due to extension of inflammatory fibrotic process up and down the urethra on either side of injury.

In his editorial comment Morey ${ }^{[14]}$ in his editorial comment concluded that patients who underwent endoscopic procedures after primary realignment often tend to expose to complications. Urethra is subjected to trauma due to subsequent self-catheterizations, emergent dilatations and other unfortunate complications. Also in a recent comparative study, he concluded that high rate of adverse events in the primary realignment group such as time taken to achieve catheter-free state, increased ( $>6$ months) the duration of self-catheterization, rates of failure following urethroplasty, development of pelvic abscesses and incontinence in primary realignment patients. ${ }^{[15]}$

Leddy et al. ${ }^{[12]}$ favor early urethral realignment via endourological methods based on literature and their own experience. Though realignment leads to higher rates of stricture recurrence it spares significant number of patients from further need of subsequent surgery.

Most of the studies favoring early endoscopic realignment have rather small sample size, few of them have a prospective design, and suffered from a bias of a successful endoscopic procedure for a less severe pelvic fracture. We have highlighted the results of the studies in Table 1. The only study with 'sizeable' sample is by Mouraviev et al. ${ }^{[2]}$ with 96 patients but authors were not very clear as to why they used endoscopic means initially even in the delayed urethroplasty group, and they were successful in up to $53 \%$ of that subset. This procedure may lead to less severe pelvic urethral injuries in different population of patients. In a comparison of contemporary series of management of pelvic fractures, Kulkarni et al. ${ }^{[16]}$ associated different rates of urethral complications seen in Indian and Italian cohorts to faster initial 
trauma care in Italy. Not just trauma care but the modality of accidents, the mean age of the population affected, the mechanism of trauma and associated non-pelvic injuries all affect the outcomes of endoscopic realignment or open surgical repair.

The endoscopic alignment is performed usually after 1 to 14 days after the traumatic event following stabilization of the patient and gaining suprapubic access. The availability of two teams of urologists is necessary. There is no final word about primary realignment which requires urgent trauma care and two teams of urologists working in collaboration.

Primary realignment is a component of initial trauma care and it might be one of the multiple factors responsible for less severe pelvic fracture urethral injuries in places where prompt rescue from trauma can be realized. The difference in the potency and the continence rates is not significant. Tables 2 and 3 highlight the studies on incontinence and potency rates after realignment and urethroplasty.

Though there is no convincing evidence favoring early primary realignment. Suprapubic catheter placement with delayed urethroplasty after 3 months is the standard of care across all highvolume centers.

\begin{tabular}{|lcc|}
\hline $\begin{array}{l}\text { Table 1. Rates of stricture after primary urethral } \\
\text { realignment }\end{array}$ & $\begin{array}{c}\text { Stricture after primary } \\
\text { realignment (\%) }\end{array}$ \\
\hline Mouraviev et al. ${ }^{[2]}$ & 57 & 49 \\
\hline Elliot and Barrett ${ }^{[4]}$ & 57 & 68 \\
\hline Herschorn et al. ${ }^{[5]}$ & 16 & 54 \\
\hline Kielb et al. ${ }^{[6]}$ & 8 & 50 \\
\hline Patterson et al. ${ }^{[8]}$ & 29 & 38 \\
\hline Leddy et al. ${ }^{[12]}$ & 19 & 78.9 \\
\hline
\end{tabular}

\begin{tabular}{|c|c|c|c|}
\hline & $\mathbf{n}$ & $\begin{array}{c}\text { Incontinence } \\
\text { after } \\
\text { primary } \\
\text { realignment }(\%)\end{array}$ & $\begin{array}{c}\text { Incontinence } \\
\text { after } \\
\text { delayed } \\
\text { urethroplasty }(\%)\end{array}$ \\
\hline Mouraviev et al. ${ }^{[2]}$ & 59 & 18 & 25 \\
\hline Asci et al. ${ }^{[3]}$ & 20 & 36 & 10 \\
\hline Elliot and Barrett ${ }^{[4]}$ & 57 & 4 & \\
\hline Herschorn et al..$^{[5]}$ & 16 & 0 & \\
\hline Patterson et al. ${ }^{[8]}$ & 29 & 3 & \\
\hline Tausch et al. ${ }^{[15]}$ & 38 & 6 & 0 \\
\hline
\end{tabular}

\section{Can we predict the need for inferior pubectomy?}

Anastomotic urethroplasty for PFUDD is carried by transperineal approach, which includes 4 steps. 1) Complete mobilization of bulbar urethra. 2) Developing intercrural space to promote crural separation. 3) Wedge resection of inferior pubic arch. 4) Supracrural rerouting.

For most general urologists, inferior pubectomy is challenging. Controversy exists regarding predicting the decision to perform pubectomy preoperatively.

Gap between the 2 transected urethral ends can be calculated preoperatively simultaneously using antegrade and retrograde urethrograms. Koraitim et al. ${ }^{[17]}$ devised index of elastic lengthening based on gapometry and bulbar urethrometry. They suggested that urethral gaps shorter than one-third of the bulbar urethra can be repaired by simple perineal operation. For longer gaps with short bulbar urethra, elaborated perineal approach using pubectomy or transpubic procedure is required.

\begin{tabular}{|c|c|c|c|}
\hline & $\mathbf{n}$ & $\begin{array}{c}\text { Impotence } \\
\text { after } \\
\text { primary } \\
\text { realignment }(\%)\end{array}$ & $\begin{array}{c}\text { Impotence } \\
\text { after } \\
\text { suprapubic } \\
\text { approach }(\%)\end{array}$ \\
\hline Mouraviev et al. ${ }^{[2]}$ & 59 & 34 & 42 \\
\hline Asci et al. ${ }^{[3]}$ & 14 & 36 & \\
\hline Elliot and Barrett $\mathrm{t}^{[4]}$ & 57 & 68 & \\
\hline Herschorn et al..$^{[5]}$ & 16 & 54 & \\
\hline Kielb et al. ${ }^{[6]}$ & 8 & 50 & \\
\hline Patterson et al. ${ }^{[8]}$ & 29 & 38 & \\
\hline Leddy et al. ${ }^{[12]}$ & 19 & 26 & \\
\hline
\end{tabular}

Table 4. Difference in steps of urethroplasty in India and Italy

\begin{tabular}{|lcc|}
\hline & India (n) & Italy (n) \\
\hline Simple perineal procedure & 7 & 21 \\
\hline Crural separation & 5 & 32 \\
\hline Inferior pubectomy & 66 & 24 \\
\hline Supracrural rerouting & 3 & 1 \\
\hline Abdominal transpubic repair & 6 & 1 \\
Omentoplasty without transpubic repair & 12 & 0 \\
\hline Old knife/ laser VIU & 15 & 41 \\
\hline VIU: visual internal urethrotomy & & \\
\hline
\end{tabular}


In the study of Andrich et al. ${ }^{[18]}$ in $38 \%$ of the patients the gap could not be calculated because posterior urethra could not be demonstrated radiologically. In $62 \%$ of the patients, there was no association between measured defect length and scale of subsequent surgery. Andrich et al. ${ }^{[18]}$ suggested that it is not possible to predict in advance what exactly must be done to achieve tension-free anastomosis. Surgeons preparing to repair an apparently short PFUDD cannot assume that simple repair is all that may be necessary. It is suggested that surgeon willing to repair PFUDD must be trained and be able to perform comfortably all 4 steps described above. There are not many studies aiming at predicting to perform pubectomy but occasionally closed bladder neck, and very high bladder neck can better be delineated through an MRI study. Also, MRI can help to detect any bony fragment between the bladder neck and the pubis. ${ }^{[19]}$

Kulkarni et al. ${ }^{[16]}$ published a study comparing the need for pubectomy and abdominal/perineal approaches in different population subsets in Italy and India. The differences in pathogenesis and early treatment of PFUDD greatly influenced the choice of surgical technique and the need for ancillary maneuvers during delayed posterior urethral reconstructions and its outcomes.

We have described a new protocol for performing (Magnetic Resonance Imaging) MRI in patients with PFUDD. The urologist is well versed with interpreting the images of (Computerized Tomography) CT Scan. In comparison, MRI is slightly more complex to interpret due to the use of different protocols. Radiologist usually perform MRI on empty bladder as patients have suprapubic catheter in PFUDD. We have used water as natural contrast in MRI to our advantage. We distended the bladder fully with saline, and give alfa blockers prior to MRI to facilitate bladder neck opening. Saline delivered through urethra acts as contrast. This protocol appreciably facilitates interpretation of the images similar to the ones we get at conventional RGU/MCU along with additional information supported by the MRI.

The lower edge of the contrast in posterior urethra is evaluated in comparison with the lower edge of pubic bone. If the contrast is seen above the pubic bone, inferior pubectomy most probably will be needed. If the contrast is seen below the pubic bone, then pubectomy most probably will not be needed. This technique has changed our practice. However, only $10 \%$ of the cases with complex PFUDD undergo MRI in our unit. We recommend using this new protocol whenever a MRI is ordered for PFUI. We do not suggest that MRI should replace conventional (Retrograde Urethrogram/Micturating Cystourethrogram) RGU/MCU.

Is pubectomy really necessary in progressive perineal approach Anastomotic urethroplasty is the standard of care in the majority of high volume centers for PFUDD. The principle of anasto- motic urethroplasty is to mobilize bulbar urethra and take it up to the posterior urethra to perform anastomosis. This is based on the elastic stretching capability of bulbar urethra. Bulbar urethra can be stretched to $1 / 3$ more of its total length. This means that, longer the penis, longer the bulbar urethra, and more is its stretchibility. This is an important aspect as there are regional and ethnic variations in the length of penis and eventually of bulbar urethra. Webster et al. ${ }^{[1]}$ popularized elaborated perineal approach for reconstruction of PFUI in 1983. This template has been well accepted around the globe. However there remains a controversy regarding the requirement of pubectomy in different studies.

Keizer et al. ${ }^{[20]}$ concluded in their study that ancillary maneuvers such as corporal rerouting or inferior pubectomy are seldom required for successful posterior urethroplasty. In the review of Flynn et al. ${ }^{[21]}$ inferior pubectomy with rerouting was required in $15-40 \%$ of the patients. Both of these studies highlight a population in the Western world.

Kulkarni et al. ${ }^{[16]}$ published the difference of choice of procedure for PFUI in developing and developed worlds. In Italy, Inferior pubectomy was required in $18 \%$ of an Italian, while in $58 \%$ of an Indian population where rates of redo cases increased up to 75 percent.

The requirement for inferior pubectomy and subsequent steps in progressive perineal approach is much higher in India and Asian countries as compared to the Western world. This may be related to the dynamics of trauma and anthropometric differences in pelvis in different populations. Also, as earlier noted, the stabilization and early realignment of the fracture tend to bring the two ends together hence mitigating the injury. Another factor, which is pertinent for research is the difference of bulbar urethral length in the two populations. In the Western world, urethra is longer and hence can be stretched more to achieve a tension-free anastomosis. Shorter urethra in the Eastern World may be inadequate to be stretched to optimal extent requiring pubectomy for the longer urethral gap.

\section{Spatulation of urethral ends?}

Spatulation of urethral ends is favored in anastomotic urethroplasty. The distal and proximal ends of urethra can be spatulated on either side. Flynn et al. ${ }^{[21]}$ spatulated distal urethra dorsally at 12 o'clock and proximal urethra posteriorly at 6 o'clock positions, and anastomized the cut ends to achieve an urethral caliber of at least $40 \mathrm{Fr}^{[1]}$ Hosseini et al. ${ }^{[22]}$ suggested that dorsal anterior urethral spatulation in urethroplasty is more efficient than ventral anterior urethral spatulation. In another technique, we can spatulate anterior urethra dorsally at 12 o'clock, and posterior urethra dorsally at 12 o'clock positions. 
In the Atlas of Urologic Clinics of North America in 1997 preferred spatulating anterior urethra dorsally at 12 o'clock and posterior urethra also dorsally at 12 o'clock positions. However, he would rotate the anterior urethra 180 degrees and anastomose to the posterior urethra. ${ }^{[23]}$ Turner-Warwick spatulated anterior urethra ventrally at 6 o'clock and posterior urethra dorsally at 12 o'clock positions. ${ }^{[24]}$ There have been no studies to support superiority of any particular technique over another.

The continence of patients after anastomotic urethroplasty performed for PFUDD depends on the presence of intact membranous urethra. In PFUDD membranobulbar injury can be seen. ${ }^{[25,26]}$ In patients with membranous injury, continence depends on the condition of the bladder neck. Kulkarni et al. ${ }^{[16]}$ suggested that the most ideal situation is not to spatulate membranous urethra together with dorsal spatulation of bulbar urethra.

\section{Definition of Bulbar urethra}

In the pathology of PFUDD, the posterior urethra is displaced in upward direction. The principle of surgery is to mobilize the bulbar urethra and stretch it up to the lower end of proximal urethra. This lower end is usually the membranous urethra. If the bulbar urethra is inadequately mobilized, then there is a tension on anastomosis and high chance of failure after primary repair.

As per the definition by ICUD guidelines that currently exist, penile urethra extends from the meatus to the distal edge of the bulbospongiosus muscle. ${ }^{[27]}$ The bulbar urethra extends from the proximal penile urethra to the distal membranous urethra. This means that bulbar urethra is behind the bulbospongiosus muscle.

Urethra after mobilization can be stretched up to $1 / 3$ of its length. For tension-free anastomosis the bulbar urethra has to be mobilized up to penoscrotal junction ${ }^{[1,21]}$ However due to lack of clarity in defining bulbar urethra, surgeons tend to mobilize urethra partially, which is major cause of failure of primary repair.

For all practical purposes, we recommend changing the definition of bulbar urethra. Bulbar urethra should be defined as urethra from penoscrotal junction up to membranous urethra.

In conclusion, pelvic fracture urethral injury is seen across the globe. Though the treatment and approach is well accepted across the globe, controversies do exist. There is no conclusive article addressing the controversial issues highlighted in this article. Adequate mobilization of bulbar urethra should be done up to the penoscrotal junction, irrespective of the length of the gap, Urologist should be well versed with the techniques of inferior pubectomy or transpubic approach. Posterior urethra should not be spatulated as the bulbomembranous anastomosis is performed, and continence largely depends on the condition of the membranous urethra even in PFUDD. Immediate SPC and delayed anastomotic urethroplasty after 3 months offer the best option of care for patients with PFUDD.

Peer-review: This manuscript was prepared by the invitation of the Editorial Board and its scientific evaluation was carried out by the Editorial Board.

Author Contributions: Concept - P.M.J., S.B.K.; Design - P.M.J., V.B.; Supervision - S.B.K.; Resources - S.B.K.; Materials - P.M.J., V.B., S.B.K.; Data Collection and/or Processing - P.M.J., V.B.; Analysis and/or Interpretation - P.M.J., V.B., S.B.K.; Literature Search - S.B.K., V.B.; Writing Manuscript - P.M.J., V.B.; Critical Review - S.B.K.

Conflict of Interest: The authors have no conflicts of interest to declare.

Financial Disclosure: The authors have declared that they did not receive any financial support for this study.

\section{References}

1. Webster GD, Mathes GL, Selli C. Prostatomembranous injuries: Review of literature and rational approach to their management. J Urol 1983;130:898-902. [Crossref]

2. Mouraviev VB, Coburn M, Santucci RA. The treatment of posterior urethral disruption associated with pelvic fractures: Comparative experience of early realignment versus delayed urethroplasty. J Urol 2005;173:873-6. [Crossref]

3. Asci R, Sarikaya S, Buyukalpell R, Saylik A, Yilmaz A. Voiding and sexual dysfunctions after pelvic fracture urethral injuries treated with either initial cystostomy and delayed urethroplasty or immediate primary urethral realignment. Scand J Urol Nephrol 1999;33:228-33. [Crossref]

4. Elliott DS, Barrett DM. Long-term follow up and evaluation of primary realignment of posterior urethral disruptions. J Urol 1997; 157:814-6. [Crossref]

5. Herschorn S, Thijssen A, Radomski SB. The value of immediate or early catheterization of the traumatized posterior urethra. J Urol 1992;148:1428-31. [Crossref]

6. Kielb SJ, Voeltz ZL, Wolf JS. Evaluation and management of traumatic posterior urethral disruption with flexible cystourethroscopy. J Trauma 2001;50:36-40. [Crossref]

7. Moudouni SM, Patard JJ, Manunta A, Guiraud P, Lobel B, Guille F. Early endoscopic realignment of post-traumatic posterior urethral disruption. Urology 2001;57:628-32. [Crossref]

8. Patterson DE, Barrett DM, Myers RP, DeWeerd JH, Hall BB, Benson RC Jr. Primary realignment of posterior urethral injuries. J Urol 1983;129:513-6. [Crossref]

9. Husmann DA, Wilson WT, Boone TB, Allen TD. Prostatomembranous urethral disruptions: management by suprapubic cystostomy and delayed urethroplasty. J Urol 1990;144:76-8. [Crossref]

10. Ku J, Kim ME, Jeon YS, Lee NK, Park YH. Management of bulbourethral disruption by blunt external trauma: the sooner, the better? Urology 2002;60:579-83. 
11. Singh BP, Adankar MG, Swain SK. Impact of prior urethral manupilation on outcome of anastomotic urethroplasty for post traumatic urethral stricture. Urology 2010;75:179-83. [Crossref]

12. Leddy L, Voelzke B, Wessels H. Primary realignment of pelvic fracture urethral injuries. Urol Clinic N Am 2013;40:393-401. [Crossref]

13. Mundy AR. Pelvic fracture injuries of posterior urethra. World $\mathbf{J}$ Urol 1999;17:90-5. [Crossref]

14. Morey AF. Editorial comments for the article pelvic fracture: The last 50 years L. Flint and Cryer HG. J Urology 2011;185:1772-4.

15. Tausch TJ, Morey AF, Scott F, Simhan J. Unintended negative consequences of primary endoscopic realignment for men with pelvic fracture urethral injuries. J Urol 2014;192:1720-2. [Crossref]

16. Kulkarni S, Barbagli G, Kulkarni J, Romano G, Lazzeri M. Posterior urethral stricture after pelvic fracture urethral distraction defects in developing and developed countries, and choice of surgical techniques. J Urol 2010;183:1049-54. [Crossref]

17. Koraitim M. Gapometery and anterior urethrometery in the repair of posterior urethral defects. J Urol 2008;179:1879-81. [Crossref]

18. Andrich DE, Malley KJO, Summerton DJ, Greenwill TJ, Mundy AR. The type of urethroplasty for pelvic fracture urethral distraction defect cannot be predicted preoperatively. J Urol 2003;170:464-7. [Crossref]

19. Oh MM, Jin MH, Sung DJ, Yoon DK, Kim JJ, Moon DG. Magnetic resonance urethrography to assess obliterative posterior urethral stricture: comparison to conventional retrograde urethrography with voiding cystourethrography. J Urol 2010;183:603-7. [Crossref]
20. Keizer WS, Armenakas NA, Brandes SB, Cavalcanti AG, Santucci RA, Morey AF. Simplified reconstruction of posterior urethral disruption defects. Limited role of supracrural rerouting. J Urol 2007;177:1378-82. [Crossref]

21. Flynn BJ, Delvecchio A, Webster GD. Perineal repair of Pelvic fracture urethral distraction defects: Experience in 120 patients during the last 10 years. Urology 2003;170:1877-80. [Crossref]

22. Hosseini J, Kaviani MJA, Mazloomfard MM, Mokhtarpour H. Dorsal versus ventral anterior urethral spatulation in posterior urethroplasty. Urol J 2010;7:258-61.

23. Mundy AR. Reconstruction of posterior urethral distraction defects. Urol Clin North Am 1997;5:139-74. [Crossref]

24. Turner-Warwick R. The principles of urethral reconstruction, Rob and Smith's operative surgery, Urology 4th ed. Dudley H, Carter D, Butterworths London. Urol J 1986;480-519.

25. Joshi PM, Desai DJ, Shah D, Joshi D, Kulkarni SB. Urology. Injury in pelvic fracture urethral injury is membranobulbar: Fact or Myth. Urology 2017;102:e9-e10.

26. Kulkarni SB, Surana S, Desai DJ, Orabi H, Iyer S, Kulkarni J, et al. Management of complex and redo cases of pelvic fracture urethral injuries. Asian J Urol 2018;5:107-17. [Crossref]

27. Latini JW, McAninch JW, Brandes SB, Chung JY, Rosenstein D. SIU/ICUD Consultation on Urethral Strictures: Epidemiology, etiology, anatomy, and nomenclature of urethral stenoses, strictures, and pelvic fracture urethral disruption injuries. Urology 2014;83(Suppl 3):S1-7. 